\title{
Treatment with epoprostenol reverts nitric oxide non-responsiveness in patients with primary pulmonary hypertension
}

\author{
R Ziesche, V Petkov, K Wittmann, J Kopatschka, L Stiebellehner, P Schenk, P Germann, \\ G Röder, R Ullrich, L H Block
}

\begin{abstract}
Objective-To assess whether long term treatment with epoprostenol might restore primary non-responsiveness to nitric oxide (NO) in patients with primary pulmonary hypertension.

Methods-Seven patients with primary pulmonary hypertension receiving intravenous epoprostenol continuously because of failure of NO to influence pulmonary haemodynamics during initial testing were followed over a period of 13-29 months. Afterwards, acute vascular reactivity towards NO was tested again during right heart catheterisation.

Results-Administration of NO after continuous epoprostenol treatment for a mean period of 18 months improved arterial oxygen saturation $(\mathrm{p}<0.01)$ and cardiac index $(\mathrm{p}<0.05)$, and decreased mean pulmonary artery pressure $(\mathrm{p}<0.01)$ and total pulmonary vascular resistance $(\mathrm{p}<0.01)$ in patients previously unresponsive to NO.

Conclusions-Long term treatment with epoprostenol reverts initial refractoriness to NO in patients with primary pulmonary hypertension. Thus the addition of NO to epoprostenol treatment might cause further improvement in the course of the disease.

(Heart 2000;83:406-409)
\end{abstract}

Keywords: primary pulmonary hypertension; epoprostenol; vascular reactivity

Primary pulmonary hypertension is a rare disease of unknown aetiology leading to the development of severe precapillary pulmonary hypertension characterised by impaired regulation of both pulmonary haemodynamics and vascular growth. ${ }^{12}$ The responsiveness to vasodilator treatment in patients with this disorder varies considerably. ${ }^{3}$ Some affected individuals respond initially to the pulmonary vasodilator nitric oxide (NO) but lose the ability to respond for unknown reasons during the further development of the disease. Others are non-responders from the start $^{45}$ and require treatment with epoprostenol. Continuous intravenous administration of epoprostenol has been shown to improve both pulmonary haemodynamics and survival in patients with primary pulmonary hypertension. ${ }^{6}$ Nevertheless, long term treatment with epoprostenol may cause tolerance phenomena and does not normalise haemodynamics in all affected individuals, despite the use of a sometimes rather aggressive therapeutic strategy. ${ }^{7-9}$

Importantly, however, it has been found that long term treatment with epoprostenol causes a reduction in pulmonary vascular resistance far exceeding that expected from the extent of the acute vasorelaxation. ${ }^{7}$ This suggests that epoprostenol may have additional effects on the pulmonary vasculature. As both epoprostenol and NO decrease pulmonary vascular tone by hyperpolarisation of pulmonary smooth muscle cells, ${ }^{10} 11$ we hypothesised that the partial recovery of pulmonary vascular function in primary pulmonary hypertension caused by long term treatment with epoprostenol might restore the responsiveness to NO.

\section{Methods}

Between January 1996 and January 1998, seven patients (two male, five female) with a diagnosis of primary pulmonary hypertension were given continuous intravenous treatment with epoprostenol because of failure of nitric oxide (10 to $40 \mathrm{ppm}$ ) to cause either a $20 \%$ decrease of mean pulmonary artery pressure (PAPm) and pulmonary vascular resistance (PVR) or a decrease of PAPm of at least $10 \mathrm{~mm}$ $\mathrm{Hg}$ during cardiac catheterisation. ${ }^{12}$ Treatment with epoprostenol was chosen because, in contrast to calcium channel blockers, this agent has been shown to improve pulmonary haemodynamics, symptoms, and survival in patients with primary pulmonary hypertension. ${ }^{6}{ }^{11}$

The diagnosis of primary pulmonary hypertension was based on clinical assessment, the results of right heart catheterisation, echocardiography, spiral computed tomography of the pulmonary arteries, pulmonary angiography, ventilation/perfusion lung scan, and complete lung function testing. Secondary pulmonary hypertension from heart disease, pulmonary disease, sleep associated disorders, chronic thromboembolic disease, autoimmune or collagen vascular diseases, HIV infection, or liver disease was excluded.

Mean pulmonary artery pressure, cardiac output, mean systemic arterial pressure, pulmonary capillary wedge pressure (PCWP), mixed venous oxygen saturation $\left(\mathrm{SvO}_{2} \%\right)$, and systemic arterial oxygen saturation $\left(\mathrm{SaO}_{2} \%\right)$ were measured by right heart catheterisation (Swan-Ganz catheter, Baxter, Irvine, California, USA). The patients were studied in the semirecumbent position. Catheterisation was performed in an intensive care unit. All patients 
Table 1 Patient characteristics and haemodynamics at baseline. Clinical characteristics, haemodynamic values of the pulmonary and general circulation, and arterial and mixed venous oxygen saturation before treatment with epoprostenol

\begin{tabular}{|c|c|c|c|c|c|c|c|c|c|c|}
\hline Patient & $\begin{array}{l}\text { Age } \\
\text { (years) }\end{array}$ & Sex & NYHA & $\begin{array}{l}P A P m \\
(m m \mathrm{Hg})\end{array}$ & $\begin{array}{l}A P m \\
(m m ~ H g)\end{array}$ & $\begin{array}{l}P C W P \\
(m m \mathrm{Hg})\end{array}$ & $C I\left(l / \mathrm{min} / \mathrm{m}^{2}\right)$ & $\begin{array}{l}P V R I \\
\left(U / m^{2}\right)\end{array}$ & $\begin{array}{l}\mathrm{SaO}_{2} \\
(\%)^{2}\end{array}$ & $\begin{array}{l}\mathrm{SvO}_{2} \\
(\%)^{2}\end{array}$ \\
\hline \multicolumn{11}{|c|}{ Before inhalation of $\mathrm{NO}$} \\
\hline 1 & 25 & M & III & 63 & 87 & 10 & 2.7 & 5.7 & 93 & 62 \\
\hline 2 & 49 & $\mathrm{~F}$ & III & 61 & 71 & 7 & 2.6 & 6.4 & 92 & 58 \\
\hline 3 & 50 & $\mathrm{M}$ & IV & 38 & 71 & 10 & 1.1 & 6.4 & 92 & 52 \\
\hline 4 & 33 & $\mathrm{~F}$ & III & 44 & 74 & 7 & 2.6 & 8.2 & 91 & 66 \\
\hline 5 & 38 & $\mathrm{~F}$ & III & 53 & 73 & 8 & 2.9 & 9.3 & 94 & 63 \\
\hline 6 & 42 & $\mathrm{~F}$ & III & 53 & 72 & 10 & 2.5 & 9.3 & 93 & 53 \\
\hline 7 & 58 & $\mathrm{~F}$ & III & 61 & 75 & 8 & 2.8 & 6.8 & 92 & 62 \\
\hline Mean & & & & $53(9)$ & $75(6)$ & $9(1)$ & $2.4(0.6)$ & $7.5(1.5)$ & $92(1)$ & $60(5)$ \\
\hline \multicolumn{11}{|c|}{ After inhalation of $\mathrm{NO}$} \\
\hline 1 & & & & 69 & 74 & 14 & 2.9 & 5.9 & 93 & 71 \\
\hline 2 & & & & 60 & 85 & 9 & 2.7 & 7.5 & 95 & 64 \\
\hline 3 & & & & 40 & 69 & 10 & 1.1 & 6.7 & 94 & 55 \\
\hline 4 & & & & 44 & 74 & 10 & 3.0 & 5.9 & 94 & 67 \\
\hline 5 & & & & 55 & 73 & 8 & 2.9 & 7.3 & 93 & 67 \\
\hline 6 & & & & 62 & 75 & 9 & 2.7 & 9.2 & 93 & 62 \\
\hline 7 & & & & 57 & 74 & 8 & 2.5 & 7.1 & 94 & 63 \\
\hline Mean & & & & $55(10)$ & $75(5)$ & $10(2)$ & $2.5(0.7)$ & $7.1(1.1)$ & $94(1)$ & $64(5)$ \\
\hline
\end{tabular}

APm, mean arterial pressure; CI, cardiac index; NYHA, New York Heart Association functional class; PAPm, mean pulmonary artery pressure; PCWP, pulmonary capillary wedge pressure; PVRI, pulmonary vascular resistance index; $\mathrm{SaO}_{2}$, systemic arterial oxygen saturation; $\mathrm{SvO}_{2}$, mixed venous oxygen saturation.

were observed on-line with an ECG, invasive blood pressure monitoring, and measurement of peripheral oxygen saturation (HewlettPackard, Böblingen, Germany). All haemodynamic and oxygen measurements were performed with a cardiac output computer (Explorer ${ }^{\circledR}$, Baxter) and a pressure monitoring kit (Baxter). Calculations were made according to standard formulas in a patient data management system (CareVue 9000®), HewlettPackard).

Nitric oxide was inhaled from a portable system providing pulsed, inspiration triggered delivery of the gas (NOXXI, Messer Austria, Gumpoldskirchen, Austria). The concentration of nitric oxide at the nasal cannulae was between 10 and 20 ppm corresponding to 2-3 $\mathrm{ppm}$ in the lower airways as assessed by intrabronchial monitoring. The concentration of $\mathrm{NO}$ and $\mathrm{NO}_{2}$ was permanently controlled by continuous measurement using a chemoluminescence detector (Ecophysics, Zurich, Switzerland) included into the NO delivery system.

Epoprostenol (Flolan, Glaxo Wellcome) was permanently delivered into the subclavian vein as been previously described, ${ }^{13}$ using a portable pump system (CADD-1, Pharmacia-Upjohn, Austria) in a dose ranging from 11 to 21 $\mathrm{ng} / \mathrm{min} / \mathrm{kg}$. The dose was adjusted as required on the basis of the clinical symptoms or from assessment of haemodynamics by echocardiography or clinical examination, carried out every month. The maximum dose of epoprostenol was $21 \mathrm{ng} / \mathrm{min} / \mathrm{kg}$ (mean, $16 \mathrm{ng} / \mathrm{min} / \mathrm{kg}$ ). In addition, the patients received conventional treatment, including diuretics and anticoagulation with phenprocoumon to sustain an INR (international normalised ratio) of 1.5 to 2.5. Observations were carried out over a mean period of 18 months (range 13 to 28 months), with both clinical and echocardiographic assessment of pulmonary hypertension. Following at least 13 months of continuous treatment with epoprostenol, assessment of acute vasoreactivity to NO was repeated.
STATISTICS

Data are given as mean (SD). Statistical analysis was performed by determination of the variance for three repeated measurements using the Wilcoxon rank sum test. All $\mathrm{p}$ values are based on two sided tests; $p<0.05$ was considered significant.

\section{Results}

Seven patients were enrolled in the study. Six were in New York Heart Association (NYHA) functional class III and one was in class IV when the treatment with epoprostenol was begun. Details of the characteristics and haemodynamics of the patients at baseline, before and after the administration of $\mathrm{NO}$, are given in table 1 . Throughout the observation period, the concentration of epoprostenol was increased at least twice in each patient because of worsening of systolic pulmonary artery pressure, assessed by echochardiographic measurement of tricuspid regurgitation. Treatment with epoprostenol was never discontinued, and there were no infectious complications or serious side effects of the treatment or delivery system.

At baseline (before start of epoprostenol treatment), the cardiac index was $2.4(0.6)$ $1 / \mathrm{min} / \mathrm{m}^{2}$ and the pulmonary vascular resistance index (PVRI) was $7.5(1.5) \mathrm{U} / \mathrm{m}^{2}(\mathrm{n}=7)$. PAPm was 53 (9) $\mathrm{mm} \mathrm{Hg}$ and PCWP was 9 (1) $\mathrm{mm} \mathrm{Hg}$. Acute vasodilator testing with $\mathrm{NO}$ did not result in significant changes of pulmonary haemodynamics (table 1). Following inhalation of $20 \mathrm{ppm}$ NO (as measured at the cannula), cardiac index changed to $2.5(0.7) \mathrm{l} / \mathrm{min} / \mathrm{m}^{2}$ and PVRI was nearly stable at $7.1(1.1) \mathrm{U} / \mathrm{m}^{2}$. PAPm and PCWP slightly increased to 55 (10) $\mathrm{mm} \mathrm{Hg}$ and 10 (2) $\mathrm{mm} \mathrm{Hg}$, respectively. $\mathrm{SvO}_{2}$ changed from 60 (5)\% to 64.0 (5) \% after NO (NS), and $\mathrm{SaO}_{2}$ from 92 (1)\% to 94 (1)\%. Systemic arterial pressure and systemic vascular resistance remained unchanged.

After long term treatment with epoprostenol and before administration of NO (fig 1), no significant changes in cardiac index or PVRI 

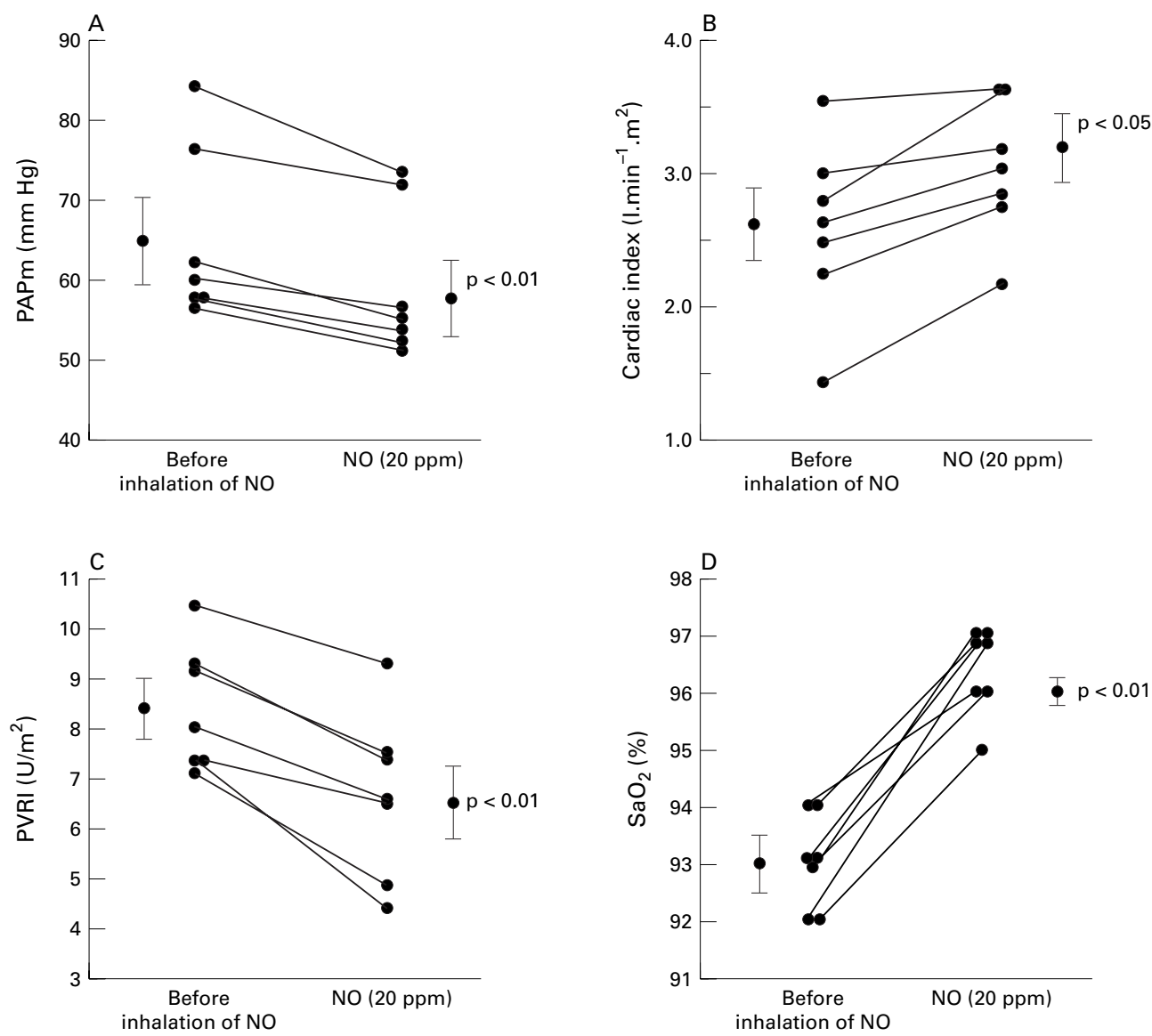

Figure 1 Effect of inhalation of 20 ppm nitric oxide (NO) on acute pulmonary vasoreactivity after continuous epoprostenol treatment in patients with primary pulmonary hypertension. (A) After inhalation of NO (10 min) during continued administration of epoprostenol, mean pulmonary artery pressure (PAPm) decreased in all patients $(p<0.01)$, while cardiac index increased in all patients $(B)(p<0.05)$. As a result, pulmonary vascular resistance index $(P V R I)(C)$ decreased by a mean of $1.7 \mathrm{U} / \mathrm{m}^{2}(p<0.01)$. As with administration of adenosine, inhalation of NO significantly increased $\mathrm{SaO}_{2}(p<0.01)$.

were observed. PAPm, however, increased to a mean of 65 (11) $\mathrm{mm} \mathrm{Hg}$, probably as a result of the comparatively low doses of epoprostenol. In contrast to the first test with $\mathrm{NO}$, the second test inhalation of $20 \mathrm{ppm}$ NO caused an

Table 2 Short term administration of NO after continuous epoprostenol treatment

\begin{tabular}{llll}
\hline Patient & $\begin{array}{c}\mathrm{APm} \\
(\mathrm{mm} \mathrm{Hg})\end{array}$ & $\begin{array}{l}\mathrm{PCWP} \\
(\mathrm{mm} \mathrm{Hg})\end{array}$ & $\mathrm{SvO}_{2}(\%)$ \\
\hline Before inhalation of $\mathrm{NO}$ & & & \\
1 & 83 & 6 & 64 \\
2 & 70 & 8 & 64 \\
3 & 73 & 9 & 51 \\
4 & 75 & 7 & 62 \\
5 & 77 & 7 & 61 \\
6 & 75 & 7 & 61 \\
7 & 76 & 7 & 62 \\
Mean (SD) & $76(4)$ & $7(1)$ & $61(4)$ \\
After inhalation of $\mathrm{NO}$ & & & \\
1 & 85 & 6 & 62 \\
2 & 83 & 9 & 68 \\
3 & 74 & 9 & 51 \\
4 & 84 & 7 & 67 \\
5 & 75 & 8 & 64 \\
6 & 78 & 6 & 63 \\
7 & 75 & 7 & 64 \\
Mean (SD) & $80(5)$ & $8(1)$ & $62(6)$ \\
\hline
\end{tabular}

Mean arterial pressure, pulmonary wedge pressure, and mixed venous oxygen saturation did not change significantly after combined administration of epoprostenol and inhalation of $\mathrm{NO}$, though there was a tendency for mixed venous oxygen saturation to rise after short term inhalation of NO.

Apm, mean arterial pressure; PCWP, pulmonary capillary wedge pressure; $\mathrm{SvO}_{2}$, mixed venous oxygen saturation. increase in cardiac index (fig 1B), by a mean of $0.5 \mathrm{l} / \mathrm{min} / \mathrm{m}^{2} \quad(\mathrm{p}<0.05)$, and a decrease in PVRI (fig 1C), by $1.1 \mathrm{U} / \mathrm{m}^{2}(\mathrm{p}<0.01)$ in all patients. PAPm decreased by $5.6 \mathrm{~mm} \mathrm{Hg}$ ( $\mathrm{p}<0.01$ ) (fig $1 \mathrm{~A}) . \mathrm{SaO}_{2}$ rose by $3.3 \%$ to 96.2 $(2.8) \%(\mathrm{p}<0.01)$ (fig 1D). $\mathrm{SvO}_{2}$ did not change significantly $(+1.6 \%$ to 62 (6)\%, $\mathrm{p}=0.073$ ) (table 2). Neither PCWP nor mean arterial pressure changed significantly $(+0.2$ $\mathrm{mm} \mathrm{Hg}, \mathrm{p}=0.603$, and $+4.3 \mathrm{~mm} \mathrm{Hg}$, $\mathrm{p}=0.135$, respectively) (table 2 ).

\section{Discussion}

In seven patients with primary pulmonary hypertension who were primary nonresponders to inhaled nitric oxide, intravenous long term administration of epoprostenol abolished the lack of responsiveness to NO, causing significant improvement in pulmonary haemodynamics. In addition, we observed an increase in arterial oxygen saturation, though mixed venous oxygenation showed only a small and non-significant increase during acute testing, probably owing to the small numbers in our sample. It is currently thought that primary pulmonary hypertension becomes a "fixed" defect, with decreased reactivity to various vasodilators. ${ }^{14}$ Nonetheless, during long term administration of epoprostenol, most patients show improved pulmonary haemodynamics, 
while initially failing to respond to NO. ${ }^{3}$ Usually, this improvement, which is never complete, is observed after hours or even days, suggesting a partial restoration of the normal contractility of the pulmonary vascular smooth muscle cells. Our results indicate that this long term effect of epoprostenol involves cellular mechanisms that account for an increase in responsiveness to the most effective pulmonary vasodilator, nitric oxide.

NO has been shown to decrease intracellular free calcium concentration, $\left[\mathrm{Ca}^{2+}\right]_{\mathrm{i}}$, in pulmonary artery smooth muscle cells, leading to relaxation of arterial tone, ${ }^{11}$ possibly by mechanisms involving the activation of voltage or calcium dependent membrane potassium channels. ${ }^{10}$ A similar effect on $\left[\mathrm{Ca}^{2+}\right]_{\mathrm{i}}$ has been reported for prostacyclin. ${ }^{15}$ Although the underlying mechanism for desensitisation of pulmonary arterial tissue to $\mathrm{NO}$ in primary pulmonary hypertension is yet unknown, it is conceivable that changes of intracellular events regulating contractility, such as changes of intracellular calcium concentration, reflect the refractoriness to NO. In line with this, it has been reported that both $\mathrm{NO}$ and prostacyclin induce hyperpolarisation in vascular smooth muscle cells ${ }^{10}{ }^{16}$ resulting in a decrease in intracellular calcium concentration. It is thus conceivable that a change in refractoriness of pulmonary artery tissue to $\mathrm{NO}$ in primary pulmonary hypertension is achieved by changes in the electrophysiology of the cells.

If confirmed during continuous treatment with both epoprostenol and NO, these data suggest that the combined effects of the two drugs may further stabilise vascular contractility of the pulmonary arteries, leading to improvement in outcome in primary pulmonary hypertension.
1 Rubin LJ, Rich S, eds. Pathophysiology of primary pulmonary hypertension. From physiology to molecular mechanisms. In: Primary pulmonary hypertension. New York. Marcel Dekker, 1997:83-130.

2 Wagenvoort C, Wagenvoort N. Primary pulmonary hypertension: a pathological study of the lung vessels in 156 clinically diagnosed cases. Circulation 1970;42:1163-84.

3 Weir EK, Rubin LJ, Ayres SM, et al. The acute administration of vasodilators in primary pulmonary hypertension. Experience from the National Institutes of Health Registry on Primary Pulmonary Hypertension. Am Rev Respir Dis 1989;140:1623-30.

4 Barst RJ. Recent advances in the treatment of pediatric pulmonary artery hypertension. Pediatr Clin North Am 1999;46:331-45.

5 Sitbon O, Humbert M, Jagot JL, et al. Inhaled nitric oxide as a screening agent for safely identifying responders to oral calcium-channel blockers in primary pulmonary hypertension. Eur Respir f 1998;12:265-70.

6 Barst RJ, Rubin LJ, Long WA, et al. A comparison of Barst RJ, Rubin LJ, Long WA, et al. A comparison of
continuous intravenous epoprostenol (prostacyclin) with conventional therapy for primary pulmonary hypertension: the Primary Pulmonary Hypertension study group. $N$ Engl f Med 1996; 334:296-302.

7 McLaughlin VV, Genthner DE, Panella MM, et al. Reduction in pulmonary vascular resistance with long term epoprostenol (prostacyclin) therapy in primary pulmonary hypertension. N Engl F Med 1998;338:273-7.

8 Shapiro SM, Oudiz RJ, Cao T, et al. Primary pulmonary hypertension: improved long term effects and survival with continuous intravenous epoprostenol infusion. $f \mathrm{Am}$ Coll Cardiol 1997;30:343-9.

9 Higenbottam TW, Butt AZ, McMahon A, et al. Long term intravenous prostaglandin (epoprostenol or iloprost) for treatment of severe pulmonary hypertension. Heart 1998; 80:151-5.

10 Zhao YJ, Wang J, Rubin LJ, et al. Inhibition of $\mathrm{K}(\mathrm{V})$ and $\mathrm{K}(\mathrm{Ca})$ channels antagonizes NO-induced relaxation in pulmonary artery. Am f Physiol 1997;272:H904-12.

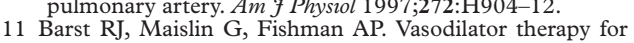
primary pulmonary hypertension in children. Circulation 1999;99:1197-208.

12 Rich S, ed. Primary pulmonary hypertension. Executive summary from the World Symposium on Primary Pulmonary Hypertension, Evian, France, September 1998:17.

13 Higenbottam $\mathrm{T}$, Wheeldon D, Wells $\mathrm{F}$, et al. Long-term treatment of primary pulmonary hypertension with continuous intravenous epoprostenol (prostacyclin). Lancet 1984;i:1046-7.

14 Gaine SP, Rubin LJ. Primary pulmonary hypertension. Lancet 1998;352:719-25.

15 Alli AI, Barette WE, Cunnane S, et al. Prostaglandin I2 (prostacyclin) inhibits intracellular calcium release [ab(prostacyclin) inhibits intracellular calcium
stract]. $\mathcal{F}$ Physiol (Lond) 1978;276:P40-1.

16 Siegel G, Mironneau J, Schnalke F, et al. Vasodilatation evoked by $\mathrm{K}^{+}$channel opening. Prog Clin Biol Res evoked by $\mathrm{K}^{+}$ch
1990;327:299-306.

17 Hoehn T, Krause M, Hentschel R. High-frequency ventilation augments the effect of inhaled nitric oxide in persistent pulmonary hypertension of the newborn. Eur Respir $\mathcal{F}$ 1998;11:234-8. 